\title{
Childhood adversity and substance
}

\section{misuse}

\author{
Anita Ambreen Taj, Eamon Keenan, Patricia Casey
}

Ir J Psych Med 2008; 25(1): 29-30

\begin{abstract}
There is a strong link between childhood adversity and subsequent substance misuse. We describe a case of childhood adversity consisting of physical and sexual abuse, experience of homelessness in childhood and adulthood, intimate partner violence and polysubstance misuse in a 32 year old woman currently attending the methadone maintenance programme in the Drug Treatment Centre Board, Trinity Court, Dublin. The relevant literature to the case is reviewed in relation to the aetiology and symptoms of this complex case.
\end{abstract}

Key words: Childhood adversity; Substance misuse; Homelessness; Aetiology.

\section{Introduction}

Emotional and behavioural disorders are common in abused children. ${ }^{1-3}$ By adolescence this can result in some cases, both of violence with psychopathic personality, and of deliberate self harm and suicide. An increased incidence of post-traumatic stress disorder is additionally reported in victims of severe physical abuse. Although these findings emerge from studies that compare maltreated children with controls from similar socio-economic groups and neighbourhoods, the families of the abused children often had disproportionately high levels of ongoing adversity and deprivation which may confound the aetiology. It is therefore sometimes hard to disentangle the effect of the abuse from the chronic deprivation. Where there are multiple stressors of this kind, the rate of psychopathology may increase disproportionately. ${ }^{4}$

There is now compelling evidence from well conducted case control studies that sexual abuse during childhood is followed by higher rates of depression and anxiety during childhood and early adult life, greater incidence of deliberate self harm and eating disorders during adolescence and early adult life. ${ }^{5,6}$

\section{Case report}

$E$ is a 32 year old, single lady who has a history of poly-

\footnotetext{
*Anita Ambreen Taj, Special lecturer in Psychiatry, The Mater Hospital, 63 Eccles St, Dublin 7, Ireland. Email:

beenataj@yahoo.co.uk

Eamon Keenan, Consultant Psychiatrist in Substance Misuse, Drug Treatment Centre Board, Trinity Court, 30-31 Pearse St, Dublin 2, Ireland.

Patricia Casey, Consultant Psychiatrist, Department of Adult Psychiatry, The Mater Hospital, 63 Eccles St, Dublin 7, Ireland. ${ }^{*}$ Correspondence

SUBMITTED: JULY 3, 2007. ACCEPTED: SEPTEMBER 28, 2007.
}

substance misuse since the age of eight. She was born to a mother who abused alcohol. She grew up in a home where she regularly witnessed her father physically abusing her mother. Her parents separated when E was four.

$E$ has been homeless on and off since the age of nine. Her mother was drinking heavily and felt she could not cope with caring for $E$. Her mother used to lock her out of the house but sometimes E's stepfather would let her stay in the house.

She was taken into state care around the age of 10 and was placed in several foster homes. However E kept running away from these homes and was sleeping rough in a deprived region of Dublin by the age of 11 . She was allegedly gang raped at 11 and became pregnant. Her mother arranged an abortion for her and following this $\mathrm{E}$ moved in temporarily with her biological father. Her father allegedly started sexually abusing her by touching her inappropriately.

At $13 \mathrm{E}$ was living in an apartment by herself and was being paid social welfare. She got pregnant at the age of 13 by her partner who was four years older than her. This relationship lasted for three years.

At 13 she was introduced to prostitution by a friend who misused drugs. She was also allegedly sexually abused by her friend's partner. Since then $E$ has been working as a commercial sex worker.

$E$ has a history of unstable relationships since the age of 13. She has had four long-term relationships. Her second partner was a heavy drinker and used cannabis excessively and was physically abusive towards her. She has been with her current partner for the last seven years. He is a recovering heroin user and is currently in prison.

She has three children aged 17,16 , and 14 who are alive and well. Her youngest child died within 12 hours of birth. All her children are in foster care and $E$ has limited contact with them. Her children were taken into care as $E$ was unable to look after them because of her substance misuse.

E started drinking at eight. Her use of alcohol rapidly escalated and by the age of 13 she was drinking 16 units of alcohol every day. Her average consumption of alcohol was 112 units per week. (The maximum recommended levels of weekly consumption are 21 units for a man and 14 for a woman). She used to drink with friends and had limited adult supervision.

She used solvents on one occasion at the age of 11 and started smoking cannabis at 13. She was introduced to heroin by her partner (at the time) at the age of 19. She initially smoked heroin intermittently but began smoking daily within one year. She first injected heroin at the age of 25 and currently uses heroin every day.

She has experimented with other drugs including cocaine, amphetamines and unprescribed codeine containing medication but has never been a regular user of these drugs. 
She started a methadone maintenance programme in The Drug Treatment Centre Board, Trinity Court, Dublin in February 2005 . She is currently prescribed methadone $80 \mathrm{mg}$ daily. Her attendance has been poor. She has failed to meaningfully engage with the staff and still continues to use heroin by subcutaneous injection in addition to her prescribed methadone. She suffers from multiple abscesses because of her use of heroin. She remains homeless and continues to work as a sex worker and these factors make it difficult for her to attend the programme at the Drug Treatment Centre Board, Trinity Court. Her life on the streets also exposes her to physical beatings from her clients.

She was diagnosed with epilepsy at the age of six which is well controlled with medication.

E was referred to a child psychiatrist for behavioural problems at the age of 12 . She was diagnosed with depression by her general practitioner in her early 20 s and was treated with antidepressants. As a teenager she cut herself superficially on the wrists on several occasions. She described these episodes as a 'cry for help' and on these occasions she did not wish to end her life. At the age of 23 she took an overdose of methadone and her antiepileptic medication and 20 units of alcohol. She was admitted to hospital for observation for 24 hours on this occasion. She made a serious suicide attempt six years ago at the age of 28 when she took an overdose of diazepam $900 \mathrm{mg}$, flurazepam $900 \mathrm{mg}$, carbamazepine $18,000 \mathrm{mg}$ and methadone in excess of $1,500 \mathrm{ml}$. She was found in an unconscious state by her boyfriend and was treated in the Mater Misericordiae Hospital, Dublin. She remembers feeling disappointed that her suicide attempt was unsuccessful.

She has attended supportive counselling sessions on a few occasions for her depression and deliberate self harm but has found it difficult to engage with treatment.

\section{Discussion}

$E$ has a history of severe neglect in childhood and her mother was a heavy drinker. In turn E's drug use led to her children being taken into foster care.

In 1999, the WHO Consultation on Child Abuse Prevention drafted the following definition:

"Child abuse or maltreatment constitutes all forms of physical and/or emotional ill-treatment, sexual abuse, neglect or negligent treatment or commercial or other exploitation, resulting in actual or potential harm to the child's health, survival, development or dignity in the context of a relationship of responsibility, trust or power".?

Drug or alcohol abuse by a parent, or worse both parents, increases the seriousness of the situation and is a contributing factor in creating an environment harmful to children. The families with substantiated child neglect are struggling with adversity, poverty, domestic violence, isolation, crime and mental health disorders. Drug and alcohol abuse is therefore not the direct cause of child neglect but but a contributing factor in that it impairs parents' ability to take care of their children. ${ }^{8}$

There is an association between childhood adversity and adult psychiatric disorder including substance misuse. A study has demonstrated associations between retrospectively reported childhood adversities and subsequent onset and persistence of DSM-III-R disorders. ${ }^{9}$ Twenty six adversities were considered, including loss events (eg. parental divorce), parental psychopathologies (eg. maternal depression), interpersonal traumas (eg. rape) and other adversities (eg. natural disaster). These adversities were consistently associated with onset, but not persistence of DSM III-R mood disorders, anxiety disorders, addictive disorders, and acting out disorders.

Another study examined the relationship between childhood sexual abuse and mental health in adult life in a random community sample of women. ${ }^{10}$ There was a positive association between reporting abuse and greater levels of psychopathology on a range of measures. Substance abuse and suicidal behaviour were also more commonly reported by the abused group. Childhood sexual abuse was more frequent in women from disrupted homes as well as in those who had been exposed to inadequate parenting or physical abuse.

\section{Conclusion}

E's history indicates an important relationship between homelessness, childhood neglect and substance misuse and is in accordance with studies reporting that chronically homeless individuals often reported experiences of severe childhood trauma and tended to attribute their continued homelessness to a substance abuse problem. ${ }^{11}$ Public policy initiatives are essential to meet the needs of homeless children. These children often do not receive adequate care from the catchment area services which are currently in place. There is an urgent requirement for resources to be directed towards the needs of homeless children. Social services need to work in collaboration with child psychiatric services to overcome barriers to accessing services that are available for this vulnerable population group

\section{Declaration of Interest: None.}

\section{References}

1. Felitti VJ et al. Relationship of childhood abuse and household dysfunction to many of the leading causes of death in adults: the Adverse Childhood Experiences (ACE) study. AM J Prev Med 1988; 14: 245-58.

2. Kendlar KS, Bulik CM, Silberg J, Hettema JM, Myers J, Prescott CA. Childhood sexual abuse and adult psychiatric and substance use disorders in women. Arch Gen Psychiatry 2000; 57: 953-9.

3 . Springs FE, Friedrich WN. Health risk behaviours and medical sequelae of childhood sexual abuse. Mayo Clinic Proc 1992; 67: 527-32.

4. Widom, Spatz C. Childhood victimization, Early Adversity, Later Psychopathology, Nat Inst Justice J 2000.

5. Beitchman JH, Zucker KJ, Hood JE, daCosta GA, Akman D, Cassavia E. A review of the long-term effects of child sexual abuse. Child Abuse Negl 1992; 16(1): 101-18. 6. Wonderlich SA, Brewerton TD, Jocic Z, Dansky BS, Abbott DW. Relationship of childhood sexual abuse and eating disorders. J Am Acad Child Adol Psychiatry 1997; 36(8): 1107-1115.

7. Report of the Consultation on Child Abuse Prevention, 29-31 March 1999, WHO, Geneva. Geneva, World Health Organization, 1999 (document WHO/HSC/PVI/99.1). 8. Mayer M, Lavergne C, Baraldi R. Substance abuse and child neglect: Intruders in the family. 2004

9. Kessler RC, Davis CG, Kendler KS. Childhood adversity and adult psychiatric disorder in the US National Comorbidity Survey. Psychol Med 1997 Sep; 27(5): 1101. 19.

10. Mullen PE, Martin JL, Anderson JC, Romans SE, Herbison GP. Childhood sexual abuse and mental health in adult life. Br J Psychiatry 1993; 163: 721-732.

11. Morrell-Bellai T, Goering PN, Boydell KM. Becoming and remaining homeless: a qualitative investigation. Issues Mental Health Nurs 2000 Sep; 21(6): 581-604. 